\title{
FRACTIONATION OF THE ISOTOPES OF OXYGEN IN A COMMERCIAL ELECTROLYZER-A CORRECTION
}

\section{By Edgar R. Smith and Mieczysław Wojciechowski ${ }^{1}$}

In a previous publication, ${ }^{2}$ there was reported an investigation of the electrolytic fractionation of the isotopes of hydrogen and of oxygen under the conditions prevailing in a commercial hydrogen-oxygen electrolyzer. It was found that after an amount of water approximately equal to 10 times the volume of a commercial alkaline cell has been electrolyzed, a steady state is closely approached in which no further isotopic fractionation occurs. In this state the gases evolved have the isotopic composition existing in the water repeatedly added to the cell. A sample of this residual "equilibrium" water was subjected to an isotopic analysis consisting in successive treatments with dry ammonia gas, to normalize isotopically its hydrogen content, until the density had apparently decreased to a constant value. However, an error has now been found in the calculation of one of the densities, which made the results appear to agree after the third and fourth ammonia treatments. This error was discovered in an effort to account for the discrepancy between the results reported and those obtained recently at Princeton University on the electrolytic concentration of oxygen isotopes. ${ }^{3}$ The purpose of this paper is to report the error and also to report a redetermination of the isotopic composition of "equilibrium" water from alkaline electrolyzers.

For this new analysis, a sample of water was obtained from the cells of the Southern Oxygen Co., South Washington, Va., and was first reduced in our electrolyzer to about half the original volume, because the equilibrium water from the Southern Oxygen Co. has been shown to be somewhat less heavy than corresponds to true equilibrium. ${ }^{4}$ After this preliminary treatment, the water was distilled from the potassium hydroxide and treated with ammonia gas as follows. A sample of about $500 \mathrm{ml}$ was placed in a liter flask immersed in a bath of acetone and carbon tetrachloride contained in in a 4-liter dewar tube. "Anhydrous" ammonia gas was passed over solid potassium hydroxide to insure dryness and then through a safety trap into the sample until the volume of the sample was approximately doubled and the flask was filled. Meanwhile the sample was kept just at its freezing temperature by additions of solid carbon dioxide to the bath. A reflux condenser was then attached to the flask and the sample boiled until its volume was reduced to the original size. After nine such treatments, the sample was freed from ammonia and other nonaqueous impurities, and the difference between its density and that of purified normal water was measured at

1 Guest worker from the Polytechnic Institute, Warsaw, Poland.

2 E. W. Washburn, E. R. Smith, and F. A. Smith, J. Research NBS 13, 599 (1934) RP729.

3 P. W. Selwood. H. S. Taylor, J. A. Hipple, Jr., and W. Bleakney, J. Am. Chem. Soc. 57, 642 (1935).

4 See footnote 2. 
$25^{\circ} \mathrm{C}$ by the use of differential pycnometers described in a previous paper. ${ }^{5}$ The difference in density was found to be $11.1 \mathrm{ppm}$. The sample was then submitted to two more ammonia absorptions and after purification was found to be $11.3 \mathrm{ppm}$ heavier than normal water, the two values agreeing well within the precision of $1 \mathrm{ppm}$ of the measurements and showing that the sample had attained the same composition with respect to hydrogen as the ammonia. The latter was shown to have normal isotopic composition by comparing the density of ordinary purified water with ordinary water which was twice treated with ammonia in the manner just described, before purification. The difference in density was less than $1 \mathrm{ppm}$.

When the corrected value of $11 \mathrm{ppm}$ is used for the increase in density caused by heavy oxygen, the electrolytic fractionation factor for the hydrogen isotopes becomes 3.5 instead of the value 2.4 reported previously.

Assuming the $0^{17}$ isotope to be negligible in amount, the separation factor, $\alpha$, for the oxygen isotopes, defined as the ratio of $0^{18} / 0^{16}$ in the electrolyte to that in the oxygen gas evolved, can be computed from the composition of equilibrium water as follows. In the normal oxygen evolved from equilibrium water $\left(0^{18} / 0^{16}\right)=1 / 500$ while in the electrolyte $\left(0^{18} / 0^{16}\right)=(1+11 / 220) 1 / 500$ and $\alpha=(1+11 / 220) / 1=1.05$. It is interesting to compare the actual decrease in density of the water formed by combining with normal hydrogen the first electrolytic oxygen from normal water with the decrease computed with the aid of this separation coefficient. The computed decrease is $220(1-1 / 1.05)$ $=10.6 \mathrm{ppm}$ as compared with the measured decrease of $13.2 \mathrm{ppm}$. The agreement is adequate since a small change in $\alpha$ results in a relatively large change in the calculated decrease in density. For example, if $\alpha=1.06$ the calculated decrease in density is $12.5 \mathrm{ppm}$. The value of 1.05 for $\alpha$ during the initial stages of electrolysis is larger than has recently been reported, ${ }^{6},{ }^{7}$ but is in fair agreement with the fractionation factor of 1.04 calculated from the results of Green and Voskuyl. ${ }^{8}$

\section{SUMMARY}

The electrolytic fractionation factor for $0^{16}$ and $0^{18}$, defined as the ratio of $0^{18} / 0^{16}$ in the electrolyte to the same ratio in the oxygen gas evolved by electrolysis, has been found to be 1.05. An isotopic analysis of "equilibrium water" from a commercial electrolyzer indicates that about $11 \mathrm{ppm}$ of the increase in density is a result of enrichment in heavy oxygen, and the value of $31 \mathrm{ppm}$ previously reported is incorrect.

One of us ${ }^{9}$ wishes to express gratitude to the Polish Fundusz Kultury Narodowej in Warsaw for financial aid.

Washington, June 4, 1935.

\footnotetext{
5 E. W. Washburn and E. R. Smith, BS J. Research 12, 305 (1934) R P656.

${ }^{6}$ See footnote 3 .

7 H. L. Johnston, J. Am. Chem. Soc. 5\%, 484 (1935).

8 C. H. Green and R. J. Voskuyl, J. Am. Chem. Soc. 56, 1649 (1934),

${ }^{9}$ M. Wojciechowski.
} 